\title{
85319 - AVALIAÇÃO DA PREVALÊNCIA DE POLIFARMÁCIA EM IDOSOS INSTITUCIONALIZADOS
}

\author{
Apresentação Oral - Geriatria
}

\author{
Alessandra Santos Menin / Menin, AS / ULBRA; Crissiane Melo Nepomuceno / Nepomuceno, CM / \\ ULBRA; Paulo Roberto Cardoso Consoni / Consoni, PRC / ULBRA
}

Introdução: com o aumento da expectativa de vida da população, aumenta o contingente de portadores de doenças crônicas, que necessitam do uso de medicamentos.Porém,o grande número de medicamentos e as alterações inerentes ao processo de envelhecimento aumentam a vulnerabilidade aos eventos adversos a medicamentos, seja por reações adversas, seja por interações medicamentosas ${ }^{1}$. Objetivo: avaliar a prevalência de polifarmácia em idosos institucionalizados e quais as principais classes medicamentosas em uso. Metodologia: estudo transversal realizado em 2018 numa ILPI municipal, em Canoas, RS. Todos os idosos residentes a partir dos 60 anos participaram do estudo.Para a coleta de dados, foram analisadas as medicações de uso contínuo contidas nos prontuários de cada idoso e utilizado o critério de polifarmácia como sendo o uso de cinco ou mais medicamentos. Resultados: a amostra final foi de 48 idosos, sendo que apenas um foi excluído por ter idade inferior a 60 anos. A faixa etária variou entre 61 a 96 anos, sendo 45,8\% do sexo masculino e $54,2 \%$ do feminino. Apenas $33,3 \%$ usa menos de 5 medicamentos, sendo que, nesse grupo, $50 \%$ utiliza 4 . Ademais, $22,9 \%$ usam 5 medicamentos, 8,33\% usam 6, 22,9\% usam 7, 6,25\% usam $8,4,16 \%$ usam 9 e 2,08\% usam 11, sendo esse o número máximo de medicamentos utilizado. Além disso, o sexo masculino apresentou uma média de 5,7 fármacos, enquanto o feminino de 5. Em relação aos medicamentos utilizados, $68,7 \%$ dos idosos toma algum anti-hipertensivo, $50 \%$ antiplaquetários, 43,7\% inibidores seletivos de receptação da serotonina, 39,5\% neurolépticos, 35,4\% benzodiazepínicos, 35,4\% anti-epiléticos, 23\% hipoglicemiantes, 14,6\% anti-parkinsonicos e 8,3\% inibidores da colinesterase. Conclusão: os grupos de medicamentos mais utilizados na prática de polifarmácia refletem a alta prevalência de doenças cardiovasculares e diabetes entre a população idosa, assim como quadros de insônia, ansiedade e estados confusionais. No estudo realizado, também foram essas as doenças que implicaram num maior uso de medicações, apesar de a presença de diabetes não ter sido uma das mais prevalentes. Ademais, tendo em vista que $66,7 \%$ dos idosos da amostra apresentam polifarmácia, o estudo vai de encontro ao que a literatura revela sobre os altos índices de polifarmácia nessa população.

Palavras-chave: idosos, polimedicação, institucionalização.

Referência: 1. Carvalho MFC, et al. Polifarmácia entre idosos do Município de São Paulo Estudo SABE. Rev Bras Epidemiol. 2012. 